mandas reais das famílias kaiowá sejam atendidas, e que os saberes fornecidos pela escola sejam eficazes e sirvam como "instrumentos de luta" (:103). É bom lembrar, mais uma vez, que Tonico Benites, indígena ava kaiowá, em sua análise se debruça sobre a sua história e a de seu povo. Este é mais um motivo para recomendar a leitura deste livro.

LUGONES, Maria Gabriela. 2012. Obrando en autos, obrando en vidas: formas y fórmulas de protección judicial en los tribunales prevencionales de menores de Córdoba, Argentina, a comienzos del siglo XXI. Rio de Janeiro: E-papers/LACED/Museu Nacional. 224 pp.

\section{Larissa Nadai}

Doutoranda - PPGCS/IFCH/UNICAMP

O livro de Maria Gabriela Lugones se debruça sobre exercícios de poder administrativo-judicial envolvendo "menores" crianças e adolescentes em conflito com a lei penal - e seus pais/guardiões. Circunscrevendo sua pesquisa aos Juizados Prevencionais de Menores na cidade de Córdoba, Argentina, entre os anos de 2005 e 2008, este livro é resultado de sua tese de doutorado defendida em 2009, no Museu Nacional - UFRJ.

Exposto desta forma, talvez não faça jus à sensibilidade e à força analítica imbricadas nos argumentos e nas imagens construídas pela autora no decorrer das páginas de seu livro. Adjetivos que se fazem necessários, pois Maria Gabriela Lugones não se deixa enfeitiçar pelas abstrações que comparecem em muitos trabalhos dedicados a etnografar instâncias estatais. Nesse sentido, seu trabalho não postula aquilo que os Juizados Prevencionales de Menores deveriam ser. Ao contrário, Lugones aceita se aventurar a descrever, com minúcia e precisão, as práticas e as atuações que constituem o cotidiano de gestão imposto a esses Juizados.

Assim, em sua etnografia, somos arrebatados pela imagem de longos e barulhentos corredores que, abarrotados de crianças, adolescentes, mães, pais, tutores, funcionárias e empregadas do Juizado de Menores, fazem parte de uma equação de somas sempre contingente entre esperas, escutas, impressões, aconselhamentos e compromissos. Ou, ainda, pela imagem do incessante abrir e fechar de portas, permitindo o acesso a salas e a "expedientes", documentações e formas de gestão, os quais, sob a identificação de "Prevenção", caminham pelos meandros burocráticos judiciais.

Estas descrições levam o leitor a experimentar, por meio da própria forma de narrar escolhida por Lugones, um cotidiano de trabalho impregnado por dinâmicas fragmentadas, miradas sempre parciais, cortes abruptos. Forma de escrita que dá carne, cheiro e densidade emocional às dinâmicas de interação gestadas nesses tribunais; "causas" que nos são contadas, elas mesmas, por expedientes narrativos sempre inacabados e dramáticos. A avó que deseja conseguir a visita dos netos ao filho preso. A jovem Susana, a qual, defronte da empregada que "leva sua causa", com os olhos marejados d'água, implora para não lhe tirarem a guarda dos filhos. Ou, ainda, o abuso sexual sofrido por Franquito e denunciado por sua mãe. Todas essas histórias, assim como inúmeras outras, atravessam o cotidiano do Juizado de Menores e nos são contadas sob a forma de "fragmentos" "fragmentos" estes que aparecem como instrumento narrativo, mas também como estratégia metodológica.

Escolha feita e levada a cabo como forma descritiva, que busca captar a própria mecânica do poder administrativo-judicial que toma a infância como objeto de intervenção moral. Textualidade que visa capturar a atuação sempre fragmentada 
dessas administradoras. Fragmentação compreendida como "condição de possibilidade" em relação aos obstáculos que dificultam o cotidiano de trabalho - a sobrecarga de trabalho, a falta de recursos materiais, humanos etc. Sob o título "Premissas e itinerários de investigação", o capítulo I do livro de Lugones nos coloca a par de suas escolhas narrativas e metodológicas, bem como de sua própria trajetória acadêmica. Este capítulo introdutório serve, portanto, de bússola e de "croqui" para as páginas seguintes.

No capítulo II, "Codificações, ideários e autos de Proteção da Criança", Lugones analisa os inúmeros ordenamentos jurídicos nacionais e locais que embasam a ação dos Juizados de Menores: o Código Civil argentino, a legislação de Proteção Integral da Infância e normativas internas formuladas pelo Foro de Menores. Alinhavada a uma espécie de "vulgata dos direitos da criança", essa legislação, contudo, não é tomada como sinônimo de atuação. Trata-se, na verdade, de um tipo de declaração de princípio, que serve de pano de fundo para as práticas realizadas nos Juizados de Menores e, exatamente por isso, pode ser estendido, torcido e burlado no cotidiano de trabalho. Assim, essas mudanças legais - tanto do contexto nacional argentino, como nas resoluções específicas formuladas pelo estado cordobês - são contrapostas às plataformas políticas e teóricas - "vulgata dos direitos da criança" - com o intuito de descreverem um tipo de linguagem moral, léxico no qual a infância e seus direitos podem ser interpelados. Daí a importância de codificar essas remissões normativas, com vistas a entender como elas ressoam na "consciência jurídica, moral e social" (:19) daquelas que, "formadas em Menores", devem atuar nesses Juizados.

Dando sequência à sua argumentação e desconfiando da premissa legal e simbólica que dá centralidade aos juízes de direito,
Lugones coloca sob rasura os muitos trabalhos que olham para os Tribunais Judiciais pressupondo sua forma de atuação através de organogramas divulgados e reforçados institucionalmente no discurso formal. É pelos mesmos motivos que a autora também coloca em suspensão os expedientes impressos, os quais, mediante assinaturas e carimbos, decantam sob a forma de documentos oficiais as muitas ações que formam a "causa", o processo judicial. Por sobre esta arguta proposta jaz a primeira "ideia-força" de seu trabalho.

Ao pôr em relevo as atuações expressas sob a reiterada responsabilidade de "Sua Senhoria" - a juíza - Lugones descortina a atuação dessas "pequenas juízas" que "levam a causa" no contato direto com crianças, adolescentes, seus pais, mães ou tutores legais. Ao evidenciar as muitas margens de manobra que a atuação de funcionárias e empregadas goza nesses Juizados de Menores, a autora nos faz considerar o espaço arquitetônico do Palácio da Justiça. Sem perceber, somos levados de mãos dadas com Maria Gabriela Lugones a flanar por corredores, salas de atendimentos, despachos e assessorias. Nódulo central de suas análises, tanto no capítulo III: “Uma administração (não) tão pública", quanto no capítulo IV: "Gestões de Pequenas Juízas", Lugones apresenta ao leitor o cotidiano de trabalho desses Juizados de Menores. Se, no capítulo III, o uso do espaço do Palácio da Justiça se constitui como "via privilegiada para o conhecimento das modalidades de gestão" (:89), no capítulo IV é a própria gestão que está sob as lentes analíticas da autora.

Expondo como se arquiteta uma "administração (não) tão pública", Lugones nos mostra as muitas esperas intencionais e estratégicas experimentadas por crianças, adolescentes e familiares em meio aos corredores da Justiça. Corredores afeitos à gestão de impressões e opiniões sobre 
aqueles que devem esperar, os quais, defronte das portas, serão administrados. Portas, pelas quais se separa e se dá passagem, se convertem crianças e adolescentes em "menores" e se mantêm pais e tutores em posições liminares de poder. Portas que, também, conduzem a salas. Salas que, sem "reserva" auditiva e visual, circunscrevem atuações e, com "reserva", dificultam o acesso de advogados. Salas que protegem as atuações dessas administradoras e produzem opacidade a elas. Finalmente, arquitetura que serve de cenário aos critérios pelos quais situações são transformadas em processos judiciais; que separam as denúncias que "se tomam" daquelas que "não serão tomadas".

Decisões que nos colocam a par daquilo que dá nome ao capítulo IV do livro: "Gestões das Pequenas Juízas". "Formadas em Menores", essas profissionais secretárias, subsecretárias e empregadas "levam a causa". Para tanto, elas operam como "repositórios de saberes" (:153), ou seja, integram em si mesmas uma espécie de unificação dessas muitas atuações fragmentárias e pontuais que são o "tudo que é uma audiência". Neste capítulo, a autora mostra as sofisticadas técnicas de memória utilizadas por essas profissionais, bem como as muitas formas pelas quais essas "pequenas juízas" vão "modelando e modulando a gestão" (:153), com o intuito de "sobre(levar) a causa". Por "sobre(levar) a causa", Lugones conceitualiza o tipo de atuação dessas empregadas, a saber, um engajamento empático que, ao mesmo tempo em que é capaz de estabelecer um vínculo cognitivo-afetivo com administrados, não se deixa "quebrar" diante deles. Em outras palavras, forma de gestão capaz de se manter a uma certa distância da dor e do sofrimento apresentados, mas que também constitui uma espécie de "faro" que baliza e forma essas empregadas.

Sublevando os relatórios técnicos, são as impressões e o exercício cotidiano de gestão - a "experiência em Menores" - que permitem a transmissão do conhecimento ao longo do tempo e da experiência no Foro. Assim, Lugones, ao dar centralidade à atuação dessas "pequenas juízas", mostra-nos como não pesa sobre essas gestões cotidianas a eficácia de uma "gramática de responsabilidade burocrática". Não se trata dos futuros juízos aferidos às atuações ou às medidas e aos procedimentos burocráticos acionados por essas profissionais. Trata-se de um outro tipo de ansiedade. Uma preocupação moral e profissional associada à ideia de "tranquilidade da consciência" impregnada em cada escolha tomada no decorrer de uma "causa".

Finalmente, todos esses fios encontram uma última tecedura no capítulo $\mathrm{V}$ que encerra seu livro: "Técnicas de Minorização". É por meio dele que uma segunda "ideiaforça" do texto de Maria Gabriela Lugones é apresentada. Inspirada pela obra de Antonio Carlos de Souza e Lima, esta segunda "ideia-força" busca desvelar as formas de minorização - formas de tutela - conformadoras das práticas de atuação dessas administradoras que "levam a causa". "Formas de aconselhamento" e "fórmulas de compromisso" vão sendo tramadas com eficiência, com vistas a gerir não só aqueles legalmente consagrados, como os "menores", mas também seus pais e guardiões, esses "maiores (i)responsáveis" que permanecem em posições relativamente subordinadas no decorrer dessa administração judicial e estatal.

Assim, são exercícios de poder estatal que engendram, mediante aconselhamentos e compromissos, diferentes engajamentos entre administração e administrados. No primeiro caso, técnicas com efeitos pedagógicos visando indicar os modos "aceitáveis" de ser/tornar-se responsável. No segundo caso, fórmulas que buscam extrair dos administrados certa quantidade de compromissos que deverão ser cumpridos mediante o risco 
sempre reiterado de virem a perder seus filhos. Em outras palavras, ambas as técnicas aparecem como ferramentas que estendem e perpetuam a autoridade estatal sobre a vida desses "menores" e seus "maiores (i)responsáveis" - "técnicas de minorização" que estabelecem uma espécie de "coextensividade" entre esses Juizados Prevencionais de Menores e as casas e as famílias, nas quais esses "menores" devem permanecer guardados.

Por fim, tramando as costuras que ainda restam soltas, o livro de Maria Gabriela Lugones não é apenas referência fundamental àqueles que se veem às voltas com temas relacionados à infância e às modalidades de gestão administrativas estatais, mas é, sem dúvida, um exemplo ímpar para aqueles que buscam inspiração teórica e etnográfica. E isso só é possível porque Lugones conseguiu, com sua escrita limpa e honesta, dar peso analítico à frase enunciada logo no título de seu livro: "obrando em autos", essas funcionárias, empregadas e juízas estavam também e fundamentalmente "obrando em vidas".

MELLO, Marcelo Moura. 2012. Reminiscências dos Quilombos: território da memória em uma comunidade negra rural. São Paulo: Terceiro Nome. 267 pp.

\section{Cauê Fraga Machado \\ Doutorando - PPGAS/MN/UFRJ}

O livro de Marcelo Mello traz a um público mais amplo as histórias e as memórias da Comunidade Negra de Cambará, no Rio Grande do Sul, estado situado no imaginário social brasileiro como um "estado branco". Este motivo já faz do livro leitura importante para aquele que deseja conhecer melhor a história do negro no Brasil, a partir do caso do Rio Grande do Sul. Além disso, a obra apresenta debates em torno do conceito de quilombo na historiografia e na antropologia em suas interfaces com os movimentos sociais, a justiça, a Nação e a Comunidade de Cambará. Demonstra a importância do trabalho para pensar o que vem se chamando de quilombo e as conceitualizações em torno dos debates sobre identidade étnica e racismo, ação política, sentidos de justiça, políticas de reconhecimento, moral, territorialidade e invenção - temas que parecem povoar a quase totalidade dos estudos sobre esses grupos.

É digna de nota, também, a reflexão sobre a natureza da construção dos dados empíricos, fundada na relação entre antropólogo e pessoas da Comunidade mediada por um projeto universitário de extensão e pela posterior participação na elaboração do laudo antropológico. Desta forma, a construção da etnografia, da pesquisa em arquivos e das reflexões de cunho sociológico é apresentada ao leitor no contexto em que foi produzida. Assim, a questão central do livro, "o papel assumido pela memória na dinâmica identitária em Cambará" (:156), é constantemente confrontada com o contexto de sua "criação/invenção" - no sentido aferido por Roy Wagner (não inventado a partir do nada, estando em jogo os diferentes "estilos de criatividade"). É esta "criatividade/inventividade" que aparece como objeto interessante para pensar a memória acionada que visa responder a questões ligadas à demarcação das terras como mais do que uma ação "interessada" de lembrar, sendo também um ato "inventivo", rico em significação. Alarga-se o estudo para além da identificação com finalidade política para a conquista de direitos, proporcionando refletir sobre a memória e a lembrança em si e sua articulação com diferentes esferas da vida em Cambará, desde o passado até o presente e o futuro.

O livro é composto por uma introdução, seis capítulos e considerações finais sobre 